\title{
POLÍTICAS PÚBLICAS E AVALIAÇÃO: ONDE ESTAMOS PARA ONDE VAMOS?
}

\author{
ViViane De Assis Ramos ${ }^{* *}$
}

\section{RESUMO}

Este artigo tem como objetivo primordial socializar estudos desenvolvidos anteriormente e provocar discussões e reflexões sobre a temática "avaliação em Educação Física", segundo a proposta elaborada pelo Governo através dos Parâmetros Curriculares Nacionais. Buscamos em uma análise dos PCNs e das contribuições de importantes autores da área da Educação e da Educação Física construir algumas proposições, que apontem possíveis saídas e contraponham as práticas avaliativas excludentes e ao papel seletivo e discriminatório que predominam atualmente nas avaliações escolares.

PALAVRAS - CHAVE: Educação - Educação Física - Avaliação - PCNs.

\section{AVALIANDO A AVALIAÇÃO}

V

ivemos hoje um cenário social historicamente complexo e fortemente subjugado pelas determinações político-ideológicas que visam a atender a interesses microssociais e econômicos do capitalismo multinacional pela via hegemônica da globalização econômica, social e política em patamares planetários. Em linhas gerais, esse processo significa uma reoxigenação do modelo capitalista agonizante por meio da perspectiva de expansão de mercados, da redução da intervenção do Estado nas áreas

\footnotetext{
* Texto produzido a partir de trabalho monográfico desenvolvido como um dos critérios para a conclusão do Curso de Especialização em Educação Física Escolar da FEF/UFG - 98, sob o título PCNs e Avaliação em Educação Física: Caminhos e Descaminhos.

** Professora do CEPAE - UFG e Professora da Rede Municipal de Ensino de Goiânia.
} 
sociais e do conhecimento transfigurado na forma de produtos tecnológicos. Em meio a todas essas transformações mundiais surgem as contradições: de um lado, os avanços e os progressos nas áreas da informática, robótica, medicina e outras; e, de outro, a pobreza e a miséria geradas pelo desemprego estrutural, pelos subempregos, pela alta concorrência no mercado e pela substituição cada vez em maior do homem pelas máquinas.

$\mathrm{O}$ atual contexto configura-se historicamente na virada deste século, transformando as relações econômicas, ultrapassando fronteiras e desregulamentando mercados nacionais. Em conseqüência, explode a desigualdade social, com a exclusão de direitos sociais básicos como emprego, educação, saúde, moradia. Trata-se, portanto, de um liberalismo revestido agora de uma nova máscara: o denominado neoliberalismo, que substitui os antigos princípios de liberdade, igualdade, fraternidade e justiça social, por valores como produtividade, eficiência, qualidade e livre concorrência.

Sob as bases de um Estado Mínimo, o mercado passa a estabelecer novos traços tanto em forma de cultura, idéias, sentimentos, valores e educação, quanto na vida social mais ampla. Com esta estratégia o modelo de privatização passa a ser concebido como uma espécie de cura para os males existentes no campo da vida social humana uma vez que o próprio Estado se mostrou incapaz de solucioná-los adequadamente.

Para alguns pensadores da pós-modernidade e grande parte dos ideólogos da nova ordem mundial, estamos em plena 3. ${ }^{a}$ Revolução Industrial. Nessa nova era da informática e robótica, o mercado se renova passando a exigir um outro tipo de trabalhador, não mais especialista como na era fordista/taylorista, mas um trabalhador versátil, autônomo, participativo e com maior capacidade de abstração.

A Educação que historicamente sempre reproduziu os interesses da classe hegemônica na sociedade agora deve atuar no sentido da construção desse sujeito ideal e, ao mesmo tempo, construir ideologicamente novas justificativas no tocante às desigualdades sociais, buscando o velho respaldo nas teorias superadas de que as diferenças são naturais, variam de acordo com o grau de experiência do indivíduo e do seu esforço pessoal, sugerindo, inclusive, que qualquer engraxate poderá desde que se esforce o bastante - ser, num futuro próximo, também um Presidente da República. 
De acordo com nossos estudos, compreendemos que a avaliação escolar, nesse contexto, tem sido a peça-chave na consecução desses objetivos, reproduzindo ao longo de sua história um modelo desqualificatório, autoritário, opressivo e excludente, por onde se consolidam as relações de poder dentro e fora da escola. Esse mecanismo, intrinsecamente indispensável ao processo de ensino e aprendizagem tem funcionado historicamente como um sistema explícito e, ao mesmo tempo ocultador, com o objetivo de controle e de poder social sobre o indivíduo para subjugá-lo às regras impostas para a manutenção do atual projeto histórico capitalista.

$\mathrm{Na}$ Educação Física não podia ser diferente. Após várias reformas e inúmeros projetos relacionados a sua pedagogia, seus conteúdos e especialmente com o processo de avaliação escolar, pôde-se constatar que o modelo teórico-científico não passou de pequenas nuances dentro da mesma perspectiva e dos interesses da classe hegemônica na formação do trabalhador que se pretendia. Se em determinados momentos históricos foi vista como remédio eficaz para curar todos os males que poderiam atingir uma nação, seja higienizando corpos, seja assumindo a função disciplinadora para formar corpos obedientes e subservientes para servir a pátria através de um processo de militarização, seja, ainda, pelo adestramento físico para aumentar diretamente a produtividade, por outro lado e mais recentemente, também tem contribuído, pela via da corpolatria e dos esportes de alto rendimento, com o estímulo à competição desenfreada e desumana, gerando expectativas individuais de saúde, padrões de beleza e lucro no supermercado da indústria do corpo. Um corpo que é ao mesmo tempo produto, mercadoria e consumidor. Tudo isso tem reforçado a utilização de práticas avaliativas classificatórias e seletivas geralmente fundamentadas em medidas ou testes que mensuravam ora as capacidades físicas, ora os comportamentos dos alunos, com o intuito de submeter seus corpos à rigidez disciplinar ou a padrões de condutas necessários à manutenção da ordem.

A avaliação tanto na Educação quanto na Educação Física tem se caracterizado historicamente por um processo uniforme, tecnicamente linear e legitimador das hierarquias sociais na qual os menos competentes vêm sendo excluídos do processo escolar, do trabalho e da riqueza produzida pelo coletivo social.

Segundo os novos padrões de acumulação, a Educação está fundamentada hoje por uma nova tendência pedagógica que Freitas 
(1995) denomina “ neotecnicismo", trazendo novamente à tona os pressupostos da educação tecnológica sob um novo conceito de Qualidade total.

Nessa perspectiva, a avaliação assume novas responsabilidades, pois agora é preciso verificar a qualidade dos sistemas educacionais, das escolas, dos professores, dos alunos, dos livros didáticos, entre outros, de forma a manter o controle do conhecimento a ser veiculado em favor da "produtividade e eficiência". A avaliação externa, que aos poucos vem sendo implementada nos sistemas educacionais, tem objetivado maniqueisticamente imprimir um sistema de avaliação, através de resultados duvidosos e questionáveis, que aponte para os problemas objetivos do ensino sem que se leve em conta a ordem política, econômica e social e o próprio papel do Estado na formação científica e cultural do País.

Diante desta realidade nada otimista para a grande maioria dos trabalhadores, urge buscar alternativas para a construção de uma outra escola e de uma sociedade que não se submeta aos moldes do modelo de produção social que se tem hoje. Não temos dúvida de que a escola tem assumido um papel meramente reprodutivista quanto às possibilidades de um novo e alternativo projeto social, porém, acreditamos que, se tomarmos a sua função educativa e social dentro do projeto políticopedagógico centralizado a partir das determinações externas advindas da organização social do trabalho, nós estaremos iniciando novas perspectivas e construindo novos objetivos para a Educação e para a Educação Física em particular, numa nova alternativa de mudança social. Avaliar neste sentido seria bem diferente de regular, verificar, mensurar para excluir e hierarquizar os conhecimentos e as pessoas no processo pedagógico da escola.

O que pretendemos nestas reflexões é encontrar pistas para tentar reverter esse quadro que, sob a forma de avaliação, massacra cada vez mais o indivíduo no seu meio e nos vários lugares sociais, dentre estes na educação, na cultura e na ciência. Nesse sentido, repensar nossa prática educacional - e, nela, a avaliação - deve ser tarefa diária, no sentido de construir coletivamente um modelo de sociedade mais humano e justa onde todos os indivíduos possam estar incluídos com condições adequadas de sobrevivência material e espiritual. Assim, precisamos planejar, reformular, discutir os rumos que a Educação e a Educação Física devem seguir para atingir estes objetivos. 
Sabemos que a Educação por si só não transforma uma sociedade, no entanto é necessário apontar para a construção de um nova prática pedagógica, que lute contra a discriminação, contra a seletividade, contra a marginalidade como forma de garantir a todos os cidadãos um ensino de melhor qualidade, direcionando-o para a formação emancipatória de sua existência pessoal e coletiva.

Daí a relevância de aprofundarmos um pouco mais os estudos sobre a categoria avaliação para que ela possa contribuir - integrada à um novo projeto de sociedade - para uma outra forma de organização do trabalho pedagógico, superando os processos segregativos de indivíduos, dos grupos, etnias, minorias sociais, entre outros. Certamente que teríamos como ponto de partida a realidade da atual escola capitalista, mas o ponto de chegada certamente seria a construção de novas relações sociais verdadeiramente democráticas em consonância com os ideais da maioria das pessoas excluídas dos bens sociais.

\section{AVALIAÇÃO... O QUE PROPÕEM OS NOSSOS INTELECTUAIS PROGRESSISTAS?}

Em nossos estudos foi possível perceber que mesmo os autores vinculados à concepção histórico-crítica da educação, têm proposições bastante divergentes no que se refere à problemática da avaliação da aprendizagem escolar na Educação e à própria Educação Física. Estas diferenças vão desde as suas formulações teórico-críticas até as indicações propositivas e metodológicas para implementação de suas idéias.

$\mathrm{Na}$ área da Educação, podemos citar Libâneo 1994, como um dos autores que desenvolve importantes proposições procedimentais, seja na discussão das teorias pedagógicas, seja nas propostas para a avaliação sob o ponto de vista da didática. $\mathrm{O}$ autor aponta a avaliação como uma tarefa didática importante para o diagnóstico e controle do trabalho desenvolvido por alunos e professores.

Nesta perspectiva, Libâneo (1994, p. 195) aponta a avaliação como

uma tarefa complexa que não se resume à realização de provas e atribuição de notas. A mensuração apenas proporciona dados que devem ser submetidos a uma apreciação qualitativa. A avaliação, 
assim, cumpre funções pedagógico-didáticas, de diagnóstico e de controle em relação às quais recorre a instrumentos de verificação do rendimento escolar.

Neste sentido, ainda que existam diferenças individuais entre os alunos, a avaliação deve contribuir para o desenvolvimento de todos os educandos, preparando-os para a vida em sociedade, tornando-os autônomos e criativos e proporcionando-lhes o conhecimento do nível de aprendizagem em que se encontram.

De acordo com este autor, a prática avaliativa deve estar aliada à unidade objetivos-conteúdos-métodos, onde a avaliação será uma forma de verificar se os conteúdos e os métodos estão adequados na consecução dos objetivos propostos pelo professor e pelo ensino.

Apesar de o autor desenvolver importantes contribuições para o campo da didática, falta-lhe, a compreensão de que as relações sociais advindas do mundo do trabalho são determinantes dos processos internos do ensino e da aprendizagem e, por conseqüência, do processo de avaliação. A ausência da categoria trabalho, como categoria explicativa das determinações externas das relações de produção, e o tipo de organização do trabalho na escola normalmente imprimem relações autoritárias e antidemocráticas, que se desdobram reproduzindo e consolidando, no interior da sala de aula, os mesmos processos avaliativos inerentes à realidade social mais ampla.

Outro autor que desenvolve importantes contribuições no campo da Educação a respeito da avaliação da aprendizagem escolar é Luckesi (1997). Ele sugere que se construa um processo de avaliação que supere as práticas classificatórias utilizadas, ora como fonte de castigo para aqueles que não adaptam ao modelo, ora como prêmio, para os que atingem os comportamentos desejados. $\mathrm{O}$ autor propõe a necessidade de realizar práticas avaliativas como instrumento de democratização do ensino. A democratização, para ele, deve ser entendida como acesso, permanência e terminalidade escolar, tendo em vista um ensino de qualidade que proporcione uma transmissão e apropriação ativa dos conteúdos escolares sempre no sentido de promover a sua emancipação.

Neste sentido Luckesi (1997, p. 35) afirma que a avaliação deve assumir a função diagnóstica, pois 
constitui-se num momento dialético do processo de avançar no desenvolvimento da ação, do crescimento para a autonomia, do crescimento para a competência etc. (...) será um momento dialético de 'senso' do estágio em que se está e de sua distância em relação à perspectiva que está colocada como ponto a ser atingido à frente.

Assim, a principal função da avaliação deve ser o diagnóstico das dificuldades do aluno para que este possa ser o ponto de partida na prática do professor e do aluno. Somente assim, então, ele pode avançar. $\mathrm{O}$ autor propõe a superação da avaliação que representa meros dados estatísticos.

Mesmo propondo uma avaliação superadora, o autor limita-se à análise da avaliação relacionada aos processos internos da relação professor-aluno - micro-avaliação em termos de sala de aula. Apesar de concordamos com as suas propostas, entendemos que a avaliação realizada pelo professor em sala de aula já vem determinada através dos objetivos que a escola assume na sua forma de organização, intrinsecamente ligada às relações de poder de produção social.

Numa perspectiva mais abrangente, encontramos em Freitas (1995) algumas das propostas mais radicais em termos de avaliação, principalmente porque ele trabalha com essa questão a partir dos seus determinantes externos. $\mathrm{O}$ autor faz uma análise conjuntural dos reordenamentos advindos das políticas neoliberais como, por exemplo, a introdução da qualidade total nas escolas, impondo um sistema de avaliação externa com o intuito de uniformizar o ensino e atender as exigências do mercado globalizado.

$\mathrm{Na}$ análise que Freitas (1995) desenvolve sobre a avaliação, um estudo da relação entre a organização do trabalho pedagógico e a didática, ele constata que estas são áreas inseparáveis e em estreita relação com o trabalho material produtivo. A avaliação da aprendizagem escolar, enquanto elemento da didática, não pode estar desvinculada da escola em sua forma de organização, dos métodos que utiliza, do conteúdo e da forma, entre outros, uma vez que estes elementos encarnam a função a ser desempenhada por ela (escola) na sociedade capitalista.

A avaliação representa a contraposição entre eliminação e manutenção. A eliminação pode ser confirmada pelo futuro destinado às classes menos privilegiadas no mundo do trabalho, pela locação destas 
em profissões menos valorizadas socialmente, ou seja, uma forma de 'eliminação adiada' - como explica o autor. Para ele, a divisão entre o trabalho manual e intelectual é um dos fatores estruturais que define, em cada indivíduo, sua função nesta sociedade de acordo com sua classe social.

Os objetivos educacionais representariam uma forma de reproduzir esta sociedade e as desigualdades presentes, sendo a avaliação um instrumento de controle para a consecução dos mesmos.

Freitas (1995, p. 224) aponta que a prática pedagógica está fundamentada por um "tripé avaliativo", constituído por avaliações instrucionais, disciplinares e de valores, no qual se estabelece o poder do professor, mantendo as atuais relações de dominação na organização social. Esse tipo de avaliação tem como principal função obter determinados comportamentos e atitudes dos alunos, tendo, como referência, um modelo de homem, mundo e sociedade previamente estabelecidos.

Normalmente as avaliações informais que o professor faz dos seus alunos, reforçadas pela avaliação formal, a fim de atender os objetivos da escola, nem sempre se situam de forma explícita na ação educativa.

Como proposta de superação das contradições nas práticas avaliativas, o autor propõe a eliminação da dicotomia entre trabalho manual e intelectual, que fragmenta o conhecimento e reforça as desigualdades sociais. Para que a avaliação deixe de ser um instrumento de hierarquização, gerador da exclusão social na escola e na sociedade, é necessário que a escola em sua forma de organização assuma outro projeto histórico e que tenha como meta principal contrapor o atual projeto capitalista.

Nesta perspectiva o trabalho material deve ser incorporado à escola como instrumento que possibilite o aluno participar da produção do conhecimento contra a gestão autoritária que tem subsidiado a escola na manutenção das relações de poder. O trabalho com valor social, reconhecido como necessidade concreta pelo coletivo, deve servir de elemento mediador entre o saber e o professor/aluno.

No campo da Educação Física, encontramos a proposta do Soares et al. (1992), que busca desenvolver uma teoria emergente com o propósito de superar a função seletiva assumida pela escola atualmente. Esta abordagem estrutura-se a partir das concepções progressistas de educação e, nela, são incorporados os discursos teórico-metodológicos de Freitas, Saviani e Vigotsky, Leontiev, entre outros. Os autores defen- 
dem uma pedagogia crítico-superadora que privilegie o acesso da classe trabalhadora ao conhecimento histórico e cultural produzido socialmente e, nessa perspectiva, à elaboração de processos avaliativos que contemplem os interesses da classe oprimida em plena articulação com um projeto maior de sociedade e de educação com vistas à sua transformação.

Avaliar na perspectiva desta pedagogia significa, sobretudo, assumi-la enquanto elemento constitutivo do processo ensino-aprendizagem e de um novo reordenamento da ação pedagógica em função do projeto político pedagógico da escola. Nesse sentido, explicitar o projeto histórico que se pretende é de fundamental importância para alcançar os objetivos desejados. A avaliação não deve ser um meio de mascarar ou distorcer a realidade - a partir de constatações pautadas numa igualdade irreal entre os alunos -, mas, sim, ser uma instrumento de leitura crítica da realidade de cada sujeito histórico-social envolvido no processo, com vistas à modificação da realidade encontrada.

De acordo com Soares et al. (1992, p. 98),

sem o reconhecimento dessas inter-relações dialéticas, como o são, por exemplo, a seleção, a retenção e a eliminação; o acesso ao conhecimento; a distinção teoria-prática em função das atribuições no processo de trabalho etc., torna-se muito difícil compreender a avaliação como elemento metodológico complexo que compõe a prática pedagógica cotidiana de professores, alunos e administradores escolares.

Na área da Educação Física escolar temos, também, as contribuições de Escobar (1997), que se aproxima teoricamente das concepções de Freitas. A autora utiliza como ponto de partida a realidade atual da escola capitalista, suas contradições e determinações, compreendendo que a luta de classes se faz presente a todo momento no interior da escola determinando suas funções e sua forma de organização, bem como, por conseqüência, as práticas avaliativas.

Neste sentido propõe uma Educação Física comprometida com a transmissão de conteúdos da cultura corporal e suas inter-relações com as determinações históricas, explícitas nos objetivos formais da escola e dos conteúdos da disciplina. A avaliação deve ser o instrumento 
fundamental na legitimação de um outro tipo de projeto histórico: o socialista.

A contribuição desses autores é essencial para que possamos reconstruir nossas práticas pedagógicas em função de outro tipo de sociedade baseada em relações sociais igualitárias. As propostas de avaliação por eles desenvolvidas vão até a raiz da questão e trazem elementos indispensáveis para que nos instrumentalizemos em favor de uma Educação e de uma Educação Física transformadora.

Estes referenciais teóricos, como se percebe, apontam para a importância da construção do projeto político pedagógico pela escola, entendendo-o como instrumento de luta e conscientização dos sujeitos do processo educativo com vistas à construção de um outro projeto hegemônico em favor dos interesses da maioria da população. Deste modo é fundamental abrir caminhos para uma nova forma de organização do trabalho pedagógico e para outras perspectivas de avaliação dentro do projeto político pedagógico que não sejam as formas tradicionais e mecanicistas da escola capitalista com base em relações autoritárias de dominação.

Nesta direção é preciso denunciar que nem sempre a função da avaliação e a função social desempenhada por ela têm sido valorizadas no projeto político da escola, uma vez que o conjunto de professores, alunos e comunidade escolar sequer consegue perceber a cristalização dos processos excludentes de que faz parte na vida social e no mundo do trabalho.

É preciso avaliarmos a avaliação que vem se apresentando no projeto pedagógico da escola e em que direção, a favor de que, quem e quais interesses ela vem se materializando no processo educacional.

\section{AVALIAÇÃO EM EDUCAÇÃO FÍSICA E A PROPOSTA DOS PCNs}

Os Parâmetros Curriculares Nacionais surgem logo após a promulgação da nova LDB em dezembro de 1996, como uma proposta que se apresenta com objetivo de se tornar um referencial de qualidade para a educação no Ensino Fundamental e Médio em todo o país. Tal documento, elaborado pelo Ministério da Educação e do Desporto preconiza, 
sobretudo, um compromisso com eqüidade, qualidade e avaliação dos sistemas escolares assumido pela nova LDB em consonância com o Plano Decenal de Educação para Todos (1993-2003).

O PCN seria, então, um referencial curricular comum para a formação escolar no Brasil com a função de subsidiar propostas de Estados e Municípios e, em certo sentido, incentivar a discussão e a prática pedagógica com o intuito de solucionar problemas de ordem nacional, tais como: os altos índices de repetência e evasão, o baixo desempenho dos alunos, a má qualidade dos professores, bem como os altos índices de pobreza, etc.

O que nos chama mais a atenção neste documento proposto pelo Governo é que o que deveria ser um referencial curricular, apresenta-se na verdade como um currículo "mínimo" pronto e acabado prestes a ser digerido pelas escolas e professores de todo o país como um pacote didático. Todos nós sabemos o quanto esta discussão e reflexão ficou restrita e pouco aprofundada com os intelectuais, professores e alunos que têm produzido conhecimento na área específica da Educação Física.

O PCN ultrapassou a própria idéia de parâmetros, para propor estruturalmente os objetivos, conteúdos, métodos, temas transversais e avaliação para cada área de conhecimento e ainda o tempo pedagógico de aprendizagem em cada ciclo, tendo como objetivo a aquisição de determinadas competências básicas pela maioria dos alunos ao final de cada etapa do ensino. Seria esta uma forma de uniformizar o ensino e garantir, via avaliação externa, que as escolas de todo o país seguissem a mesma cartilha como nos indicou Freitas? E a favor de quem estariam os objetivos e avaliação propostos nos parâmetros?

Especificamente sobre a área da Educação Física, constatamos alguns avanços principalmente quando se aponta uma concepção que deve romper com as antigas perspectivas da aptidão física, fundamentando-se em concepções de corpo e movimento que ultrapassam os aspectos meramente fisiológicos e técnicos e destacando, também, outros pontos de capital importância como as questões culturais, sociais, políticas e afetivas no tratamento dos conteúdos.

Indica-se, em termos gerais, que a avaliação deve ser qualitativa e reflexiva sobre a prática pedagógica, democrática e que auxilie o aluno na produção do conhecimento. No entanto, quando buscamos a sua proposta de avaliação para a área, encontramos objetivos implícitos que 
reforçam antigos ranços da Educação Física, atendendo aos interesses que não visam transformar a sociedade e muito menos a que aí está.

Encontramos ali uma verdadeira miscelânea de propostas pedagógicas ou divergentes em alguns pontos ou totalmente antagônicas. Senão vejamos: elementos da pedagogia construtivista piagetiana, abordagem tecnicista com a idéia de eficiência e eficácia no ensino e de aptidão física, introduzindo a perspectiva da saúde do escolar. Deparamos com os pressupostos comportamentalistas, ao mesmo tempo com aspectos da psicologia humanística e com alguns conceitos da fenomenologia. Tudo isto rebuscado por um discurso progressista que visa atualizar (ou confundir os menos avisados) reais objetivos da proposta.

A exemplo da proposta de avaliação em Educação Física para os quatro ciclos de escolarização o PCN (p. 67, 76-77) indica alguns critérios, por exemplo:

enfrentar desafios corporais em diferentes contextos como circuitos, jogos e brincadeiras; participar das atividades respeitando as regras e a organização; interagir com seus colegas sem estigmatizar ou discriminar por razões físicas, sociais, culturais ou de gênero.

(...) enfrentar desafios colocados em situações de jogos e competições, respeitando as regras e adotando uma postura cooperativa; estabelecer algumas relações entre a prática de atividades corporais e a melhora da saúde individual e coletiva; valorizar e apreciar diversas manifestações da cultura corporal identificando suas possibilidades de lazer e aprendizagem.

Os objetivos e os conteúdos presentes na proposta estão sinalizando, a todo momento, que a meta principal é a modificação de comportamentos dos alunos com vistas ao ajuste e à acomodação ao meio social. A criança deve aprender a respeitar as diferenças individuais auxiliando aqueles menos competentes (leia-se aptos). Tal orientação caracteriza-se indiscutivelmente por um modelo que contempla os mais habilidosos, devendo estes assumir uma postura solidária e bondosa ao aceitar no grupo os que não têm a mesma sorte, e assim por diante.

Deve-se inclusive avaliar, dentre os comportamentos que a criança deve adquirir, se ela suporta suas frustrações sem se tornar violenta. As diferenças não são de ordem social, mas naturais de pessoas que vivenciaram experiências diferentes, sendo papel e função dos mais habilidosos tolerar os que não têm a mesma competência no jogo. 
A teoria do esforço individual é uma constante nos conceitos presentes na proposta, uma vez que a idéia veiculada é de que as crianças menos competentes são portadoras de um déficit no plano individual, que as impede de obter o sucesso esperado. Uma justificativa excelente que explica bem as desigualdades raciais e de classe social legitimando a exclusão do aluno, via reprovação nas séries ou ciclos e tornando o problema natural no nível individual. Neste sentido a auto-avaliação é indicada como uma forma de desenvolver na criança uma auto-imagem positiva e, ainda, de incentivá-la a se esforçar mais para acompanhar os bem-sucedidos.

Encontramos, portanto, um discurso camuflado de progressista que nada mais é do que a mistura de diversas concepções pedagógicas, inclusive contraditórias e acríticas, utilizadas sem a menor responsabilidade pelo Governo, transvestida de um tipo de pseudoneutralidade científica, cultural e política. O tal sujeito crítico, autônomo, solidário, cooperativo a ser formado deve respeitar as regras do jogo (capitalista) a fim de manter relações sociais harmoniosas.

De posse de tais propostas dos PCNs, perguntamos: de qual educação e escola estamos falando? Da escola capitalista cheia de conflitos e contradições, espaço onde se travam verdadeiras lutas por diferentes interesses no seu dia-a-dia, ou de uma escola pacífica culturalmente hegemônica e socialmente igual? Será que os conflitos podem ser superados com pequenas alterações psicológicas de cunho adaptativo para modificar os comportamentos nos indivíduos?

Trata-se de uma proposta confusa, que se orienta pelo consenso entre as pessoas individualmente e que deixa no ar muitas questões que deveriam estar explícitas uma vez que os discursos oficiais afirmam tratar-se de um instrumento/canal socializador das discussões educacionais em todo país.

\section{EM BUSCA DE PROPOSIÇÕES PARA A ESCOLA QUE QUEREMOS...}

Como se pode depreender de nossas análises, a atual conjectura da lei do mercado tem se constituído no motor que impulsiona a vida social. Ao regular os interesses dos indivíduos, a globalização é apontada como sinal de progresso e modernidade, a Educação, por sua vez, orientada 
pelas elites estrangeiras, tem sido assumida pelo atual Governo como um referencial de prosperidade para o País, implementando em todos os setores da realidade social e econômica os princípios neoliberais de produtividade, eficiência, qualidade, excelência, rentabilidade, mensurabilidade, competição, livre concorrência e privatizações, culminando com a implementação de políticas que buscam reduzir cada vez mais o papel do Estado no setor social, engessando-o sob a concepção de Estado Mínimo.

Nesse contexto, surgem estratégias para a melhoria da qualidade e da eficiência educacional no sentido de atender melhor as exigências econômicas de qualificação e disciplinamento da força de trabalho.

A nova LDB garantiu as reformas educacionais subjugada pelos ditames desta nova ordem, seguindo as determinações do Banco Mundial que visam, preferencialmente, garantir a modernização da educação, o controle do repasse de verbas às escolas para que se equiparem ao padrão de qualidade que está sendo monitorado. Sob as benesses do mercado e da privatização, o governo vem retirando-se gradativamente de sua responsabilidade para com a educação e o ensino formal.

Com isto, cada vez mais, o Banco Mundial passa monitorar a Educação com o controle de seus empréstimos ao sistema educacional, através de um sistema de avaliação que será implantado nacionalmente conforme prevê a LDB. A avaliação institucional contrapõe o discurso de descentralização presente na lei e padroniza um sistema de provas na tentativa de uniformizar o ensino em todo o país.

Nesse sentido não é possível nos desvincularmos de todas as temáticas relacionadas à Educação, a Educação Física e à avaliação das políticas que o Governo vem propondo, uma vez que elas expressam interesses nem sempre ocultos e tem se materializado permanentemente na prática a partir de determinações externas à própria escola.

No caso da avaliação - enquanto categoria que juntamente com os objetivos expressam a função social da escola -, nem sempre explícita nos procedimentos internos da relação professor-aluno, ou na didática de ensino restrita ao cotidiano da escola, ou mesmo nos procedimentos verificatórios de desempenho do aluno, pode-se constatar que este instrumento está diretamente vinculado aos problemas externos enraizados na ordem social vigente que continuam consolidando o modelo de produção econômica e social sendo os PCNs um de seus veículos mais explícitos. 
Não discordamos de que as determinações advindas do mundo do trabalho, nessa era tecnológica, indicam a necessidade de se instrumentalizar o trabalhador, o que exigirá uma maior preocupação tanto das esferas privadas quanto governamentais com a qualidade na Educação. Todavia, restringir aos sujeitos sociais o acesso ao mínimo de conhecimentos para lidar com todas essas transformações e, ao mesmo tempo, poder consumir esses novos produtos é, no mínimo, reduzir o homem ao reino das necessidades, esquecendo-se dos valores que os fazem humanamente humanos.

Talvez seja esta, ao contrários dos pessimistas e derrotados, a grande oportunidade de que estávamos precisando para construir a escola que queremos. O modo de organização capitalista agoniza numa grande crise e revive, em certo sentido, um conflito de tempos atrás, entre explorar e o educar. Será que não deveríamos desde já combater radicalmente tais propostas no sentido de recuperar as propostas que historicamente construímos no campo da educação? Ou, no mínimo, não deveríamos nos aproveitar das fragilidades dessas políticas e traçar novos rumos - na prática - para a Educação e para a Educação Física?

Ainda que a LDB tenha ignorado as discussões coletivas que vinham sendo realizadas pela Câmara Federal, pelo Fórum Nacional em Defesa da Escola Pública e pelas entidades sindicais e científicas compostas por trabalhadores e educadores em geral, abriram-se brechas para que possamos construir uma prática pedagógica em consonância com os interesses da maioria.

De acordo com a nova Lei de Diretrizes e Bases, cada escola terá a liberdade de construir o seu próprio projeto político pedagógico, o que só vem abrir novas possibilidades para a Educação e para a Educação Física no redimensionamento de novas pedagogias educacionais. Entendemos que no projeto pedagógico poderão ser explicitamente travados os conflitos de interesse e de posição de classes sociais dentro da escola, pois é o momento privilegiado em que ocorrem as disputas do saber, do conhecimento científico e do poder. Devemos fazer deste um momento de construção de um projeto histórico que favoreça os interesses da maioria de trabalhadores que compõem a escola pública.

Freitas (1995, p. 102) aponta que 
a quase totalidade dos sistemas educacionais apresenta durante o período obrigatório algum tipo de divisão entre ensino acadêmico e profissional, planejados a grosso modo, para conduzir jovens, respectivamente, a postos de trabalho de gravata ou de macacão - de colarinho branco ou azul, se prefere.

Através da avaliação, essa organização elitista e hierárquica se impõe de forma autoritária na escola, uma vez que os conteúdos, métodos, objetivos da escola estarão sujeitos à avaliação que se fará dela. Com isto, reproduzem-se na escola as relações de poder entre patrão e empregado. Portanto, avaliação e objetivos, enquanto par dialético, devem ser a outra categoria central para a construção do projeto de escola que pretendemos.

Numa discussão interna sobre o projeto pedagógico da escola é importante que sejam tematizados os problemas que mexam com os interesses dos professores, pais, alunos, no sentido de construir um projeto de escolarização que atenda os anseios da maioria. Portanto, a auto-organização, a unidade metodológica, a interdisciplinaridade devem ser elementos fundamentais na intervenção do processo no sentido da mudança que precisa ser operada.

$\mathrm{O}$ que estamos propondo é que o projeto político pedagógico da escola seja o instrumento de conscientização dos nossos educadores sobre as determinações externas que têm gerado uma educação pautada em ações educativas nefastas, excludentes, injustas como são os princípios preconizados pelo neoliberalismo e pela nova face do neotecnicismo.

Trazer para a organização do trabalho pedagógico a categoria trabalho com valor social, enquanto princípio educativo, é redimensionar com conteúdos e forma um nova maneira de superar a dicotomia entre trabalho manual e intelectual que fragmenta o conhecimento, as funções que cada indivíduo deverá desempenhar na sociedade e a formação humanamente necessária ao novo homem.

A Educação Física integrada a este projeto maior dentro da escola terá a possibilidade de assumir um papel responsável na transmissão dos conteúdos da cultura corporal e instrumentalizar a classe trabalhadora para buscar sua libertação da atual situação de submissão e opressão em que se encontra. 
De olho nas contradições e nas proposições historicamente construídas pelo coletivo de intelectuais e pelas lutas sociais e políticas, entendemos ser este o grande momento para buscarmos alternativas visando reverter esse quadro. As palavras-chave são construção e intervenção. A realidade da atual escola capitalista que não queremos deve ser o ponto de partida para a escola que sonhamos e que pretendemos construir.

\section{ABSTRACT}

This paper aims to think over the theme "evaluation in Physical Education. We analized the national curricular parameter, proposed by the Federal Government, and we came to the conclusion that it is necessary to point out new evaluation forms due to the exclusion and to the prejudices, which are very common in school evaluations nowadays. KEY WORDS: Education - Phisical Education - Evaluation - National Curricular Parameter.

\section{REFERÊNCIAS BIBLIOGRÁFICAS}

BRASIL. Congresso Nacional. Lei de Diretrizes e Bases da Educação Nacional. Brasília. 20 de dez. 1996.

BRASIL. Ministério da Educação e Cultura. Secretaria do Ensino Fundamental. Parâmetros curriculares nacionais: Educação Física - versão preliminar. Brasília, 1996.

ESCOBAR, Micheli. Transformação didática. Construção da teoria pedagógica como categorias da prática pedagógica. Campinas, 1997. Tese (Doutorado) - Universidade de Campinas.

FREITAS, Luiz Carlos. Crítica à organização do trabalho pedagógico e da didática. São Paulo: Papirus, 1995.

LIBÂNEO, José Carlos. Didática. São Paulo: Cortez,1994.

LUCKESI, Cipriano Carlos. Avaliação da aprendizagem escolar: estudos e proposições. São Paulo: Cortez, 1997.

SOARES, Carmem Lúcia. TAFFAREL, Celi Neuza et al. Metodologia do Ensino da Educação Física. São Paulo: Cortez, 1992. 